tion as to how far it is applicable to the data submitted for discussion.

Dr. Hunter published the clata for discussing the rainfall at Madras during the six sun-spot cycles, ending 1876 , these being all the available data for Madras. As regards the sun-spots, we certainly have no positive data earlier, at least, than these cycles, whatever value may be attached to the approximate earlier figures supplied by Dr. Wolf. As regards, therefore, both the elements under discussion, viz., the sun-spots and the rainfall, the period discussed by Dr. Hunter represents the whole of the cycles for which material is available.

In dealing with this period, Dr. Hunter divides it into six equal cycles of eleven years each, this being substantially the average duration of the sun-spot cycles. I have arranged the relative numbers published in Wolf's last list (Wolf. Astronomische Mittheilungen, pp. 35-37), according to the cycles adopted by Dr. Hunter, with the result that all the six minimum years of sun-spots occurred either in the first year of the cycle, or in one of the immediately adjoining ones on either side of it, viz., in the second or in the eleventh years. As regards the years of maximum sun-spot, five out of the six occurred in the fifth or sixth years of the cycle, and the remaining year of maximum sun-spots occurred in the eighth year.

In his paper Dr. Meldrum states that as the sun-spot cycles are not all of the same length, it is evident that, by starting from any one year and going backwards over a long period, always using the same fixed number, a maximum and a minimum year might fall into the same group, and it was to obviate the occurrence of this contingency which the above analysis of Dr. Hunter's method shows did not occur during the period discussed by him, that Dr. Meldrum has proposed his new rnethod as a more accurate mode of discussing the data.

To test the value of this new method of inquiry, $I$ have arranged Wolf's relative numbers of sum-spots in accordance therewith, the maximum year of sur-spots of each cycle being placed in the sixth year, the minimum years being marked with an asterisk, and the "mean cycle" of eleven years being calculated from the thirteen years in the manner described by Dr. Meldrum :--

\begin{tabular}{|c|c|c|c|c|c|c|c|c|c|}
\hline Year. & $181 x-2$ & 82. & $832-4$ & $x^{8} 43-55$ & $1855-67$ & $1865-7$ & Means & $\begin{array}{l}\text { Niean } \\
\text { cycle. }\end{array}$ & $\begin{array}{c}\text { Year } \\
\text { of } \\
\text { cyrle. }\end{array}$ \\
\hline I & 16 & 8.5 & $26 \cdot 3$ & ${ }^{*}{ }^{*}{ }_{3} \cdot{ }$ & 77 & $3 \times 4$ & 547 & & \\
\hline 2 & 49 & $x 6.2$ & ${ }^{\circ} 94$ & 39 & ${ }^{*} 5 \mathrm{x}$ & 147 & it6 & 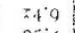 & 1 \\
\hline 3 & 126 & $35^{\circ} \circ$ & 133 & $3^{5} 3$ & $22^{\circ} 9$ & $* 8$ & 21.8 & 27 & 2 \\
\hline 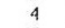 & 16.2 & $51^{\circ} 2$ & $59^{\circ} 0$ & $59^{\circ} 6$ & $56 \div 2$ & 36.8 & 46.5 & $4^{538}$ & 3 \\
\hline 6 & $35^{\circ} 2$ & $62^{\circ} 1$ & $119^{\circ} 3$ & $97^{\circ} 4$ & $90^{\circ} 3$ & $7^{8} \cdot 6$ & 80.5 & $77^{\circ} 0$ & 4 \\
\hline 6 & $46^{\circ} 9$ & 67.2 & ${ }^{1} 3^{6} 9$ & 1249 & $94^{\circ} 8$ & $131 \cdot 8$ & 1004 & $91^{\prime} 1$ & 5 \\
\hline 7 & $39^{\circ} 9$ & $67^{\circ}$ & ro $4^{\circ} \mathrm{I}$ & $95^{\circ} 4$ & 77.7 & III38 & $83^{\circ} 0$ & $\begin{array}{l}83^{\circ} \circ \\
60^{\circ} \cdot x^{2}\end{array}$ & 6 \\
\hline & & $50^{\circ} 4$ & $83^{\circ} 4$ & $6 \cdot 8$ & $6 \mathrm{r}^{\circ}$ & $99^{\circ} 7$ & 657 & 65.6 & 7 \\
\hline 9 & 235 & 26.3 & $6 r^{-8}$ & 63.2 & 45.4 & 677 & 48 & $49^{\circ} 0$ & 8 \\
\hline I0 & 16.2 & & $3^{8 \cdot} \cdot 5$ & 527 & $45^{\circ} 2$ & $43^{\circ} x$ & $34: 2$ & $34^{\circ} 6$ & 9 \\
\hline II & 6.1 & $\times 3.3$ & $23{ }^{\circ} \circ$ & $3^{8 * 5}$ & $3: 4$ & 18.9 & $2 x^{\prime} 9$ & $24^{\circ} 6$ & I0 \\
\hline 12 & $\begin{array}{r}3.9 \\
* \\
*\end{array}$ & $59^{\circ}$ & ${ }^{*}{ }_{1}{ }^{*} 1$ & $21 \%$ & 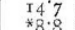 & $\begin{array}{ll}11.3 \\
*\end{array}$ & 20.5 & 22.5 & II \\
\hline${ }^{13}$ & & $x \times 9^{\circ} 3$ & 193 & 77 & & & 27.5 & & \\
\hline
\end{tabular}

It will be seen from this table that with this arrangement the year of minimum sun-spots has occurred on the tenth, twelfth, thirteenth, first, second, and third years. By Dr. Hunter's arrangement the minimum years fell within a compact group of three consecutive years out of a cycle of eleven, whereas by Dr. Meldrum's arrangement they are scattered over seven years out of a cycle of thirteen. Further, I find that in the second cycle what is virtually a maximum year (viz., 1836 with 119.3 of sun-spots) fell within his minimum group, or in the thirteenth year. This is precisely the result which the method was designed to avoid, but as to the occurrence of which there was not an approach under Dr. Hunter's arrangement.

Again, if the same relative numbers of Wolf be arranged as Dr. Meldrum proposes, so that the year of minimum sun-spots of each cycle be placed in the ninth year of the thirteen years, it will be found that the maximum years are scattered over the twelfth, thirteenth, first, second, third, and fifth years of the series. By Dr. Hunter's method of arrangement five out of the six maximum years fell in the fifth and sixth years of the series, while the remaining one fell in the eighth year, thus again presenting a compact group, whereas Dr. Meldrum's method scatters them over more than half of his series of thirteen years.

An objectionable feature of this new method is the necessary repetition of figures which it involves. Thus, in the table given above, embracing six cycles, nine minimum years occur; and in the table in which all the minimum years are so arranged as to stand in the ninth year of the cycle, nine maximum years also occur, so that if the Madras rainfall were cliscussed by this method, the averages would be computed from tables in which the maximum and minimura years occur eighteen instead of twelve times.

Mr. Meldrum's method might be improved if he entirely struck out the first and thirteenth years of the thirteen years series, and simply "bloxamed" the remaining eleven years for the years of his "Mean Cycle;" that is, made the first of these years the mean of the eleventh, first and second; the second year the mean of the first, second and third. Even, however, with this change the method is inferior to that employed by Dr. Hunter, and the force of this statement wili be the more readily recognised if it be kept in mind that we have no positive data from which the relative numbers of the sun-spots can be calculated prior to the time when Schwabe began his great work of sun-spot observation.

Edinburgh, April 22

Alexander Buchan

\section{Trajectories of Shot}

Mr. NIVEN was perfectly welcome to make use of my experi ments and tables, as he has done, in trying to devise new methods of calculating trajectories of shot. And when he had satisfied himself that his methods possessed some advantages over others, he required no excuse whatever for their publication. But I altogether object to NIr. Niven's rule for finding $z_{\beta}$ being connected in any way with the mode of calculation adopted by we. I beg, therefore, to place side by side Mr. Niven's rule, to which I object, and my rule, which I make use of, and so leave the matter. Mr. Niven says respecting $v_{\beta}^{\prime}:-$

"The first steps in our work must be to guess at it. The practiscd calculator can, from his experience, make a very good estimate. Having made his estimate he determines $k$. Ife uses the value of $k$ in equation (a), and if he gets the velocity he guessed at, he concludes that he guessed rightly, and that he has got the velocity at the end of the arc. If equation (a) does not agree with him he makes another guess, and so on till he comes right."

The following is the course I pursue to find $v_{\beta}$. Refer to the table of coefficients and take out the value of $k_{a}$ corresponding to the initial velocity $z_{a}$. Substitute in equation (a) and find a first approximate value of $v_{\beta}$. Now determine the nean valuc of $k$ between $v_{\alpha}$ and $v_{\beta}$ just found, substitute in equation (a), and thus find a second approximate value of $\tau_{\beta}$, which will gencrally be found sufficient. Otherwise adjust by proportional parts.

In this way the value of $v_{\beta}$ is found accurately on the supposition that $k$ has remained constantly at its mean value between $\tau_{\alpha}^{\prime}$ and $v_{\beta}$. Here the operations are of the simplest kind, and no guessing or practised calculator is required. And with a view to diminish the tedimn of malking these calculations, tables of $\Sigma(k), \Sigma(k \div g),(\text { rooo } \div v)^{3}$ a, \&c., have been calculated and printed, but their publication has been delayed on account of the experiments proposed to be made with low velocities.

Since Mr. Niven described the process of guessing as " $e x$. tremaly dangerous," there can be no doubt that the epithet was "extreme." As I supposed, he is not prepared to supply me with a single practical case where his condition of danger is satisfied. And if a case camnot be found then the objection falls to the ground. Whether we consider the range of valnes of $k$ for spherical or ogival-headed shot, for velocities above $1,200 \mathrm{f}$.s., we shall find that $\frac{d k}{d v}$ lies between the limits $c$ and $-0^{\circ} 09$, or, where $k$ is a mean over an arc, between $o$ and -0.05 about. And it is the smallness of this tabular value which renders it diffecult, if not impossible, to satisfy Mr. Niven's condition of danger. But if this quantity had not been small, then the cubic law could not have been used even approximately. Mr. Niven is at liberty to take shot of any size used in practice, moving at any attain. able velocity beyond $\mathrm{r}, 200 \mathrm{f} . \mathrm{s}$., and the coefficients of resistance for either spherical or ogival-headed projectiles. The objection is Mr. Niven's, and he must take the onus of supporting it if he still thinks it of value.

I regret to have to write anything in opposition to Mr. Niven's paper, because in all other respects it appears to me a valuable contribution to the science of ballistics. F. BASHFORTI

Minting Vicarage, April i 7 